\title{
Study on Process-based Cultivation Mode for Professional Master Degree Candidates
}

\author{
Qun Xie* \\ School of Civil Engineering and Architecture \\ University of Jinan \\ Jinan, China
}

\author{
Li-ping Qiu, Shou-Bin Zhang, Yan Feng \\ School of Civil Engineering and Architecture \\ University of Jinan \\ Jinan, China
}

\begin{abstract}
Academy freedom and creation is generally advocated in the process of graduate education, however, currently the emphasis and attention has been put on the graduation thesis and the administration in the whole cultivation is relatively loose. According to the requirement of program object, more engineering practice has been participated for graduates pursuing the professional master degree. Therefore the students have to experience a twelve-month internship in enterprises to enhance the engineering ability which otherwise would lead to quality problem. A process-based supervision mode has been provided in this paper and the characteristics of objectbased multi stage evaluation have been emphasized during the whole period of studying. Key steps such as topic selection, midterm inspection and pre-defense should be strictly carried out to guarantee the academic level of graduate. As a creative mode to eliminate the disadvantage of traditional cultivation mode, this new mode is expected to present its applicability and effectiveness to meet the current requirement of emerging engineering education strategy.
\end{abstract}

Keywords-process-based evaluation; professional master degree candidates; cultivation mode; evaluation system

\section{INTRODUCTION}

Compared with the cultivation of graduate students, the studying mode of graduates are relatively flexible and it is possible that the students fail to get the master degree which will probably generate the problem that the students couldn't finish the task on time or inferior thesis [1]. The entrance examination for graduate has been unified for both in-service students and full-time students which indicates that a uniform and strict standard needs to be carried out. In order to adapt the transformation the universities have to pay more attention on the cultivation of students who want to pursue the professional master degree. In one hand these kind of students must participate the engineering practice outside the campus to improve the job competitive power in the future, on the other hand, they spend less time on the thesis writing [2].

\section{STATUS ANALYSIS}

With the amount growth of graduates, some problems have

This work is supported by Shandong Graduate Education Innovation Program Project (Grant no.SDYY16019), Shandong Professional Degree Graduate Case Base Project (Grant no. SDYAL17047) and Ministry of Education Enterprise-University Cooperation Education Project (Grant no. 201701074007). occurred in the academy level and quality as follows:

1) The lack of rational feasibility and discussion has partially occurred in the process of research topic and in some extreme cases the tutors have determined the thesis topic directly without any interaction with the students. What's more, students have no deep understanding for research field because of insufficient literature reading. The feasibility of research plan is questionable and especially the state-of-the-art research results have not been reviewed in the topic presentation. Meanwhile the tutor could not give the students enough guidance before the topic determination and constructive suggestions are seldom given due to the academic limitation [3].

2) The mid-term check will not be conducted and the evaluation results is not entirely fit the expected research achievements of research plan. Both tutors and students usually have no idea for the further work and there is no analysis for the reason of unfinished task [4].

3) The reason for the lack of scientific research skill is probably less participation in academic activities, poor innovative idea, and unsatisfactory ability in paper writing as well as insufficient literature reading. Meanwhile most students are strongly dependent on the guidance of tutor and partially lead to the inefficiency for individual thinking.

Currently graduate cultivation system is object-based administration mode which emphasizes the quality of dissertation and pay little attention on important procedures in the whole process. However, actually process-based administration is more helpful to guarantee high quality of graduate cultivation. University of Wolverhampton is the first university to adopt the ISO9000 system for graduate administration whose function is to distinguish, evaluate and control each procedures in the cultivation process and to find out the correlation between procedures in order to make the whole process reasonably connection [5].

Nowadays some domestic universities have conducted the process-based administration system in graduate education. For example, Fuzhou University has taken comprehensive reform measurements, such as thesis proposal monitoring mechanism, supplement of mid-term inspection, optimization thesis assessment procedure, and strengthening academic morality management as well as thesis external audit, to improve cultivation quality. Tianjin University has established the 
quality management assessment and monitoring system in which the participation of students, tutors, administrators and social resources has been integrated into a multi-latitude platform [6].

Wuhan University of Technology has setup the compound curriculum system based on fundamental theory and knowledge, professional quality and ability, as well as scientific thinking philosophy [7]. China Jiliang University also has attempted some measurement to enhance the effectiveness of process-based administration, such as feedback and rectification of mid-term inspection, compulsory pre-defense procedure, academic misconduct literature check (AMLC) [8].

Although there are successful experience of process-based graduate educational modes from some universities, referable cases for civil engineering graduates are not available yet. As a typical engineering discipline, not only the fundamental knowledge is needed for civil engineering graduates, but also the practical ability and creative ability is required. Therefore, it is necessary to establish a new system of process-based management and assessment [9-10].

\section{PROCEDURES OF PROCESS-BASED MANAGEMENT}

In order to achieve the goal of process-based management, the quality awareness needs to be developed in all graduate cultivation-related participants. Administration concept conversion from target-based mode to process-based mode and cultivation mode innovation are also helpful to create the multiple-level cooperation between students, tutors, administration sections and social resources [11]. In order to carry out the process-based evaluation system, measurement \& reform has to be made in the following aspects:

1) Revising the graduate education programs of civil engineering. Based on the deep understanding of current nation policy and guidance principle for master degree, the amended programs should find out the reasonable combination of student development desire and university current situation.

2) Strengthening supervision of research topic selection. Based on the deep understanding of current nation policy and guidance principle for master degree, the amended programs should find out the reasonable combination of student development desire and university current situation. For academic master students, the tutors are responsible to guide graduates for research exploration in academic frontier field. While for professional master students, practical topic with advanced engineering background is preferable.

3) Innovative systems and programs should be provided to motivate the creative motivation of students, including research projects support, excellent paper reward, and scholarship honor. Strengthening supervision of research topic selection. Graduates are motivated to apply for the innovative fund projects and each student has to finish one of the three tasks, one publication, one patent and one creative project.

4) Emphasis on academic activities. It's the tutor team, not only tutor himself, in charge of graduate cultivation. Every student needs to present his/her research result in the routine meeting once a week. All teachers and students in meeting would present academic viewpoint or research suggestion and free discussion is encouraged. Finally the tutor would summarize the meeting conclusions and open the task for each one in next meeting whose purpose is to give the student a target-aimed research training.

5) Graduate academic seminar is a beneficial platform for students academy exchange. Such annual seminar should better be organized by students themselves. Experts and scholars in civil engineering are welcome to attend the seminar to present their state-of-the-art achievements to broaden students' view sight. Also the students are funded to participate domestic and international meeting and have full discussion with young scholar all over the world.

6) Scholarship evaluation regulation emendation must be taken to add some assessment quotas, including article publication, patent, research project, academic lecture. The fundamental principle of emendation is to enhance the percent of critical procedures scores in order to urge the necessary attention and effort at each cultivation procedure.

7) Pre-defense is a helpful measurement to guarantee thesis quality prior to the formal defense. The candidates of master degree have to pass the format examination firstly and it is noticeable that the standard and procedure of pre-defense is quietly same with the formal one. The pre-defense would be organized by individual team at least two months before formal defense and meanwhile the college will also randomly select some candidates for pre-defense held by college graduate administration. Only candidates that pass the pre-defense have the qualification for the subsequent formal defense, the students failed in pre-defense have to revise their thesis for the next application according to the suggestion.

\section{CONCLUSION}

There will be 2 million graduates in 2020 according to the prediction of national education reform and development policy, however, the contradiction between quantity expansion and cultivation quality will be unavoidable. Therefore, quality improvement and guarantee is the core and urgent task for graduate education in order to accommodate with the requirement of current situation. Process-based management system is an effective and powerful tool which underlines the individual critical procedures in the whole cultivation process and provides the corresponding target and reasonable evaluation for students. In this paper, a comprehensive management and evaluation system has been established for civil engineering graduates.

Some feasible measurements are also given, such as optimization of research topic select, strict examination of midterm inspection, establishment of pre-defense, compulsory peer review of thesis. Meanwhile, necessary incentive methods have been adapted to build a platform for academic innovation and activities. The tutors have also indispensable to fulfill the guidance duty. Generally, the operation of process-based education mode is a co-operation work for students, tutors, administration officers which is meaningful to enhance the academy quality of graduates. 


\section{ACKNOWLEDGMENT}

This work is supported by Shandong Graduate Education Innovation Program Project (Grant no.SDYY16019), Shandong Professional Degree Graduate Case Base Project (Grant no. SDYAL17047) and Ministry of Education Enterprise-University Cooperation Education Project (Grant no. 201701074007).

\section{REFERENCES}

[1] Ze-Hui Yang, Yang Cong, Guo-Quan Zhou. Construction and practice of the Four-Respect Assessment System in process of Courses Teaching for Training Outstanding Chemical Engineers, Research in Higher Education of Engineering, pp. 182-186, 2015, 2. (In Chinese).

[2] Nan Shi, Bai-Xia Liu. Test mode reform of undergraduate courses for applied-oriented university. Education and Vocation, pp. 115-117, 2015 12. (In Chinese).

[3] Fei Gao, Yu-Nan Liu. Process-based examination method to motivate autonomic learning consciousness of students. Heilongjiang Education, pp. 7-8, 2015, 6. (In Chinese).

[4] Hong-Wei Yan. Practice and conceivation of process-based administration appraisal in university. Science and Technology Innovation Herald, pp. 111-112, 2013, 25. (In Chinese).
[5] Ting-Liang Wu. Research on ISEC civil engineering teaching reform project, Journal of Guiyang College(Natural Sciences edition), PP. 66-68, 2015, 02. (In Chinese).

[6] Yan-Zhou Peng, Dongi-Mei Liu, Qiao-Sen Zhu. Hierarchical teaching mode of civil engineering materials experimentation, Journal of Architectural Education in Institutions of Higher Learning, PP. 117-121, 2013, 12. (In Chinese).

[7] Yuan-Ge Wang. Supervision \& evaluation system for civil engineering graduation design. Journal of Jiujiang University (natural sciences edition), pp. 124-125, 2014, 06. (In Chinese).

[8] Yuan-Ge Wang. Process-based practical teaching reform for reinforced concrete curriculum. Journal of Educational Institute of Jilin Province, pp. 96-97, 2014, 11. (In Chinese).

[9] Ying-Zi Wang, Wen-Long Hu, Guang-Jing Xiong. Practice of Inquiry Learning Method on Introductory Course, Research in Higher Education of Engineering, pp. 180-184, 2014, 04. (In Chinese).

[10] Guo-Jie Wang, Min Chai. Teaching reform and practice of graduation design for civil engineering majors in independent college, Journal of Architectural Education in Institutions of Higher Learning, pp. 117-121, 2013, 02. (In Chinese).

[11] Yong-Mei Li, Jun Zhao, Hua Ma. Engineering quality-based teaching system construction for principles of reinforced concrete structures. Journal of Southeast University (Philosophy and Social Science edition), PP. 140-143, 2012, S2. (In Chinese). 